\title{
DEVELOPMENT AND OPTIMIZATION OF A MICROWAVE-ASSISTED EXTRACTION OF PLUMIERIDE FROM Allamanda cathartica L. FLOWERS
}

\author{
Tiago J. Bonomini, Jaqueline A. Góes, Marina da S. Machado, Ruth M. L. da Silva and Angela Malheiros* \\ Núcleo de Investigações Químico-Farmacêuticas, Universidade do Vale do Itajaí, 88302-202, Itajaí - SC, Brasil
}

Recebido em 20/07/2017; aceito em 27/09/2017; publicado na web em 13/11/2017

\begin{abstract}
A simple and efficient microwave-assisted extraction process has been developed in order to extract plumieride from Allamanda cathartica flowers. The extracts have been obtained through microwave-assisted extraction (MAE) process with ethanol and ethyl acetate at different time, power and temperatures. Static maceration at room temperature with ethanol and ethyl acetate was obtained in order to compare the efficiency of extraction. HPLC method was validated to quantify plumieride in the extracts. The analyzed parameters: linearity $\left(\mathrm{R}^{2}=0.999\right)$, precision $(\mathrm{CV} 3.3 \%)$, recovery $(98 \%)$, specificity $(97 \%)$, limit of detection $\left(1 \mu \mathrm{g} \mathrm{mL} \mathrm{m}^{-1}\right)$, and limit of quantification $\left(2 \mu \mathrm{g} \mathrm{mL}^{-1}\right)$ were satisfactory. The yield of plumieride reached $43 \%$ in the extracts under the optimal MAE conditions (10 min, $300 \mathrm{~W})$. Plumieride recoveries by conventional extraction method were $12 \%$ with ethanol and $22 \%$ with ethyl acetate. Time and power parameters on plumieride extraction yield was determined by applying a factorial design and surface plots. Ethanol was the best extractor solvent and it was possible to obtain high contents (52 $\mathrm{mg} \mathrm{g}^{-1}$ of dry flowers) at optimized conditions. It can be concluded that MAE process has actual advantages over the conventional extraction method in terms of shorter time and higher efficiency to recover plumieride from $A$. cathartica flowers.
\end{abstract}

Keywords: Allamanda cathartica; high performance liquid chromatography; microwave assisted extraction; plumieride.

\section{INTRODUCTION}

Throughout history, nature provide natural medicines for the treatment of a broad spectrum of diseases. Especially plants have been important sources of biologically active substances. This has provided the basis for pharmaceutical research and discovery of new molecules with therapeutic activity. ${ }^{1-4}$ According to the World Health Organization (WHO), about $80 \%$ of the world population depends on traditional medicine for their primary care using medicinal plants as biological source of active compounds..$^{5-8}$

Considering this fact, Allamanda (Apocynaceae) is a genus of climbing shrubs, comprising twelve species distributed throughout tropical America. Some species, like A. cathartica, A. schottii and A. blanchettii have being grown as an ornamental plant. ${ }^{9,10}$ Among the classes of secondary metabolites isolated from this genus are steroids, terpenoids, flavonoids, coumarins, lignans and iridoids. ${ }^{11-13}$

Iridoids represent a class of secondary metabolites found in a wide variety of popular medicinal plants. These are used as a bitter tonic, sedative, antipyretic, skin disorders and as hypotensive. ${ }^{14}$ Generally, possess significant anti-inflammatory, analgesic, antibacterial, antifungal, antitumor activities, antioxidant, antiviral, anxiolytic and purgative activities. ${ }^{13,15-19}$

The iridoid plumieride has been isolate from several genus like Allamanda, Himatanthus, Plantago and Plumeria in different yields. ${ }^{20-25}$ Plumieride shows antidermatophytic, antifungal, plant growth inhibitory potential and in vitro cytotoxicity against radiationinduced fibrosarcoma (RIF) tumor cells. ${ }^{19,20,26}$

Extraction of secondary metabolites with pharmacological activity has been investigated in recent decades, focusing mainly on extraction with a conventional solvent. The first step for the separation and isolation of natural products is the extraction of compounds from the cellular matrix. Traditional methods have significant drawbacks, including long extraction times, large quantities of organic solvents, intensive laboratory procedures, low yield of extraction and potential

*e-mail: angela@univali.br degradation of labile compounds. ${ }^{27}$ Several advanced extraction techniques have been developed for improvement efficiency and selectivity for extracting natural compounds from herbal medicine, including pressurized liquid extractor, microwave assisted extraction (MAE), ultrasound assisted extraction and supercritical fluid extraction. ${ }^{28-31}$

MAE is a technique that uses microwave energy to directly heat the solvent to extract target compounds from various matrices, thus accelerating the speed of heating. The highly localized temperature can cause migrations of target compounds more selectively and more rapidly (usually in less than $30 \mathrm{~min}$ ) with similar or better recovery than traditional extraction processes with the main advantages of reducing both extraction time and solvent consumption. ${ }^{27-29}$ Many studies have been published on the application of MAE of secondary metabolites from plants. ${ }^{32-34}$

In the present study, response surface methodology (RSM) was examined for optimization of MAE process parameters (solvent, irradiation power and extraction time) to obtain maximum yield of plumieride. Thus, the method was successfully developed to extract plumieride from A. cathartica flowers. To our best knowledge, there is no report about MAE of plumieride from A. cathartica.

\section{MATERIAL AND METHODS}

\section{Chemicals}

Plumieride was isolated from the extract of the flowers of Allamanda cathartica by column chromatography. The purity of the compound was assessed by high performance liquid chromatography (HPLC) and nuclear magnetic resonance (NMR) analysis, through comparison with the literature and direct comparison with original samples. ${ }^{13,21,35}$ Plumieride presented a purity $>98 \%$. Methanol and acetonitrile were purchased from Tedia ${ }^{\circledR}$ (HPLC grade). Distilled water was obtained from a Millipore Direct-Q water-purification system and used in all solutions. Other reagents are analytical grade and purchased from Tedia®. 


\section{Plant material}

The flowers of $A$. cathartica were collected in Barra Velha (26³4'14.6”S 4841'13.4”W) - Santa Catarina State in Brazil on January and February of 2011. The specimens were deposited in the Herbarium Barbosa Rodrigues in Itajaí - Santa Catarina under the code HBR 52742. Collected flowers were dried in a forced-air oven at $45^{\circ} \mathrm{C}$ to constant weight, and then ground using an electric grinder (model MA048, Marconi ${ }^{\circledR}$, São Paulo, Brazil), sieved through an insert of hole size 20 mesh, and stored at room temperature in desiccator until use.

\section{Microwave assisted extraction}

MAE extraction of A. cathartica flowers was performed using a Microwave Synthesis System $\left(\mathrm{CEM}^{\circledR}\right.$ - Discover/908005). The extracts were obtained using ethanol (E) and ethyl acetate (A) as solvent. The dried flowers $(1.5 \mathrm{~g})$ were placed in contact with each solvent in a $25 \mathrm{~mL}$ round bottom flask at $1: 10(\mathrm{~m} / \mathrm{v})$ for different extraction times (ET $=5,10$ and $20 \mathrm{~min}$ ) and microwave power (MP $=100,200$ and $300 \mathrm{~W}$ ) at a constant temperature of $50{ }^{\circ} \mathrm{C}$. After filtration, the extracts were taken to dryness in a circulating air oven at a temperature of $45^{\circ} \mathrm{C}$, and stored in a desiccator until further use. After that, the temperature of extraction was raised up to the boiling point of each solvent in order to investigate using a single-factor-test to determine the influence of temperature in the yield of plumieride in different extracts. Extractions with ethanol and ethyl acetate were performed (Tedia®- HPLC grade) at times of 5, 10 and 20 min with fixed MP of $200 \mathrm{~W}$. After, the extracts were obtained as described above. The extraction procedure was carried out in duplicate. The content of plumieride in the extracts was determined by HPLC-PDA analysis.

\section{Conventional solvent extraction (CSE)}

The dried vegetal material ( $5 \mathrm{~g}$ ) was extracted exhaustively with $50 \mathrm{~mL}$ of ethanol or ethyl acetate at room temperature by conventional solvent extraction, for a period of two, four and seven days. Solvent removal was carried out under reduce pressure in a rotary evaporator at a temperature below $50{ }^{\circ} \mathrm{C}$. Later they were taken to dryness in a circulating air oven at a temperature of $45{ }^{\circ} \mathrm{C}$. The extraction procedure was carried out in duplicate.

\section{Extraction and isolation of plumieride}

Air-dried flowers (135 g) of A. cathartica were extracted by maceration with ethanol $(1.35 \mathrm{~L})$ at room temperature for seven days, filtered and the solvent removed under reduced pressure at temperatures below $50^{\circ} \mathrm{C}$, which was dried under high vacuum to get crude extract $(50 \mathrm{~g})$. The ethanol extract of the flowers $(30 \mathrm{~g})$ was chromatographed in a silica-gel column with ethyl acetate and ethanol as solvent. The fraction eluted with ethyl acetate and ethanol (9:1) yielded plumieride. Then, it was recrystallized by methanol to yield $9 \%$ pure plumieride. The compound was analyzed by HPLC and NMR, then the data were compared with those found in the literature or with data of the standard previously isolated. ${ }^{13,21,35}$

\section{HPLC analysis}

Chromatographic analysis was carried out on a Waters ${ }^{\circledR} 2996$ HPLC system, equipped with a $600-\mathrm{F}$ quaternary gradient pump, and 717 plus autosampler with an in-line degasser and coupled to a UV-Vis detector (PDA 2996). The data were acquired and processed by Empower software (Pro version). All separation was performed using a Phenomenex Luna C18 column $(250 \mathrm{~mm}$ x $4.6 \mathrm{~mm}$ i.d. $5 \mu \mathrm{m}$ particle size) protected by a $\mathrm{C} 18$ guard column at $25^{\circ} \mathrm{C}$. The gradient system used consisted of a mixture of solvents A (methanol), $\mathrm{B}$ (acetonitrile 10\%) and $\mathrm{C}$ (water acidified with phosphoric acid at $\mathrm{pH} 3.54$ ), starting with $10 \% \mathrm{~A}, 10 \% \mathrm{~B}$ and $80 \% \mathrm{C}$ at a flow rate of 1

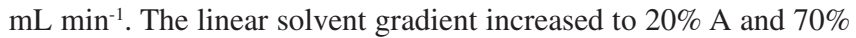
$\mathrm{C}$ in $20 \mathrm{~min} ; 20 \% \mathrm{~A}$ and $70 \% \mathrm{C}$ in $35 \mathrm{~min} ; 35 \% \mathrm{~A}$ and $55 \% \mathrm{C}$ in $50 \mathrm{~min} ; 50 \% \mathrm{~A}$ and $40 \% \mathrm{C}$ in $55 \mathrm{~min} ; 70 \% \mathrm{~A}$ and $20 \% \mathrm{C}$ in $65 \mathrm{~min}$; $50 \% \mathrm{~A}$ and $40 \% \mathrm{C}$ in $70 \mathrm{~min}$ and $10 \% \mathrm{~A}$ and $80 \% \mathrm{C}$ was maintained until the end of the run to re-equilibrate the system for baseline stability. The solvent gradient in volume ratios of $\mathrm{A}$ and $\mathrm{C}$ was as follows: 0-10 $\mathrm{min}, 10-80 \% \mathrm{C}$; 10-20 $\mathrm{min}, 20-70 \% \mathrm{C}$; 20-35 min, $35-55 \%$ C; 35-50 min, 50-40\% C; 50-55 min, 70-20\% C; 55-65 min, $50-40 \% \mathrm{C} ; 65-70 \mathrm{~min}, 10-80 \% \mathrm{C}$. UV-Vis spectra were recorded at a wavelength range of $200-400 \mathrm{~nm}$. Detection wavelength for analysis of plumieride was performed at $230 \mathrm{~nm}$ and to assess absorption profiles related to flavonoids $355 \mathrm{~nm} .{ }^{36,37}$ The solvents used were HPLC grade (high purity), filtered $(0.2 \mu \mathrm{m}$, Schleicher \& Schuell, Maidstone, Kent, UK) and degassed by sonication before use. In this chromatographic condition, the retention time of plumieride (Rt) was next to $15.4 \pm 0.1 \mathrm{~min}$. Plumieride were quantified using external standards method.

\section{Standard solutions and sample preparation}

A first stock solution of plumieride standard of $1 \mathrm{mg} \mathrm{mL}^{-1}$ was prepared in methanol. From this solution six dilutions were performed to prepare standard solutions at concentrations of $150,250,350$, $500,600,800 \mu \mathrm{g} \mathrm{mL}{ }^{-1}$, and a second stock solution of plumieride standard of $0.1 \mathrm{mg} \mathrm{mL}^{-1}$ was prepared to prepare five standard solutions at concentrations of $5,10,20,40$ and $80 \mu \mathrm{g} \mathrm{mL}^{-1}$, each of which $20 \mu \mathrm{L}$ were used for plotting the standard curve of plumieride. The samples obtained by different extraction methods and different solvents were analyzed by weighed $1 \mathrm{mg}$ and diluted in $1 \mathrm{ml}$ of a mixture of methanol, acetonitrile and acidified water $\left(0.5 \% \mathrm{H}_{3} \mathrm{PO}_{4}\right.$ $\mathrm{v} / \mathrm{v}$ ) at a ratio of 70:10:20, respectively. Each solution was then filtered through a $0.45 \mu \mathrm{m}$ membrane filter and $20 \mu \mathrm{L}$ aliquots were analyzed in triplicate.

\section{HPLC/PDA validation method}

The analytical method was validated according to the following parameters: linearity, accuracy, limit of detection (LOD), limit of quantification (LOQ), accuracy and specificity. To check the method linearity, eleven different concentrations of the standard solution were prepared, as described for the Standard Solution, ranging from 5-800 $\mu \mathrm{g} \mathrm{mL}^{-1}$. The solutions were injected in triplicate and monitored at $230 \mathrm{~nm}$. Calibration graphs were plotted subsequently for linear regression analysis of the peak area with concentration. The method precision was determined by analyzing three standard solutions containing plumieride at a concentration of $360 \mu \mathrm{g} \mathrm{mL}-1$. Each analysis was performed five times on the same day, obtaining the total of 15 injections. According to literature, the accuracy can be expressed as RSD, not accepting values above 5\%. ${ }^{38,39}$ The LOD and LOQ were determined by the method of signal-to-noise ratio $(\mathrm{S} / \mathrm{N})$ of $3: 1$ and 10:1, respectively. ${ }^{39}$ To evaluate the method accuracy a recovery experiment was performed. A known extraction solution that contain $40.32 \mu \mathrm{g}$ of plumieride were spiked with 40 , 360 and $680 \mu \mathrm{g} \mathrm{mL}^{-1}$ of standard plumieride solution. Each analysis was performed in triplicate in the same vial and this procedure was performed three times. Accuracy was calculated from the following equation: [(spiked concentration - real mean concentration)/ spiked concentration] x 100. The specificity was analyzed after subtracting the mean concentration of the known extraction that containing 
$40.32 \mu \mathrm{g}$ of plumieride from that spiked with $360 \mu \mathrm{g} \mathrm{mL}^{-1}$ of standard plumieride. The value obtained was compared with the average concentration of a solution of plumieride contained $360 \mu \mathrm{g} \mathrm{mL}^{-1}$ by a rule of three, where this solution is equal to $100 \%$.

\section{Quantification of plumieride}

Plumieride was identified by the retention time and quantified from peak area at $230 \mathrm{~nm}$ using external standard method. The value of the areas obtained in triplicates of the plumieride was recorded by Empower software. It was calculated the mean of triplicates, standard deviation (s) and RSD. to check the reproducibility of the data. The values of RSD were lower than 5\%, analyzes were considered reproducible and by the straight-line equation of the standard response curve of the marker were obtained the concentrations in the samples.

\section{Experimental design and statistical analyses}

In this present work, response surface methodology (RSM) coupled with Box-Behnken experimental design with three-level factorial design for two variables, was applied to investigate the individual and interactive effects of process variables to extract plumieride from $A$. cathartica flowers using MAE. MP and ET were the independent variables, while the extraction mass and plumieride content the response. Statistical analyses were performed using STATISTICA software version 8.0 (Statsoft). Two-way ANOVA was done to determine the effects of extraction method and ET on mass and plumieride yields, and means comparison was done by Tukey`s test with a significance level at 5\%. Considered statistically significant $\mathrm{p}<0.05$.

\section{RESULTS AND DISCUSSION}

To obtain the highest content of plumieride, the conditions of MAE were investigated. MAE process is influenced by several parameters like extraction solution, temperature, and ET. The common extraction solvent for medicinal plants are water, alcohol (methanol and ethanol), ethyl acetate, dichlorometane and their mixtures. Ethanol becomes the first choice of MAE extraction solvent as it has high solubility for many kind of metabolites. Besides extraction solvent, the microwave temperature, power and time also need optimization. In this aspect, the RSM was adopted for multi-factor optimization of MAE in this paper. Through this method it was evaluated the factors which affect the biological process and their interaction, thus improving extraction efficiency. ${ }^{34,40}$

\section{HPLC analysis}

In this work, it was developed and validated a sensitive method to analyze and quantify plumieride in extracts of $A$. cathartica flowers. The method showed a satisfactory peaks separation, mainly plumieride peak $(\mathrm{Rt}=15.4 \pm 0.1 \mathrm{~min})$, the main component in the extract, with good resolution within a short space of time using a gradient method. The Figure 1 shows the chromatograms of the extracts obtained at $230 \mathrm{~nm}$ by conventional extraction for 7 days with ethanol and ethyl acetate and the extracts obtained by MAE with ethanol (E2 - $5 \mathrm{~min}, 200 \mathrm{~W}, 50{ }^{\circ} \mathrm{C}$ ) and ethyl acetate (A2 - $5 \mathrm{~min}, 200 \mathrm{~W}, 50{ }^{\circ} \mathrm{C}$ ). The identification of plumieride was carried out by comparison of the UV spectra and retention time of previously isolated plumieride obtained under the same analytical conditions.

There is a direct relationship between chromatographic peak area and analyte concentration. It can be seen that there is a
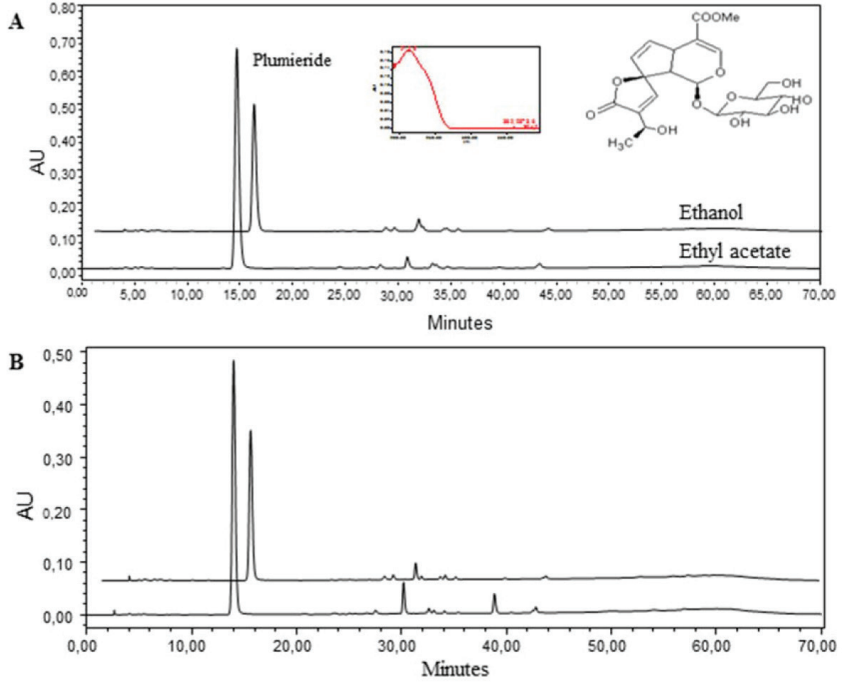

Figure 1. HPLC Chromatogram of the extracts obtained by MAE (A) and $\operatorname{CSE}(B)$ of A. cathartica flowers at $230 \mathrm{~nm}$. For Chromatographic conditions see experimental session

similarity in the phytochemical profile, wherein a difference in the concentrations could be observed. In both extracts obtained by MAE and conventional maceration the plumieride area is higher, when it was used ethyl acetate as solvent. All other extracts by MAE present similar profile to those shown in Figure 1.

The chromatographic method proposed in this work was validated to determine the LOD, LOQ, linearity, intra-day precision and accuracy, for the determination of plumieride in crude extracts and fractions. ${ }^{38,41}$ Method linearity was checked by calibration curve. The linear regression equation for plumieride was expressed as $y=33000 x-29000$, with correlation coefficient $r=0.9998$ and coefficient determining $\left(r^{2}\right) 0.9996$. ANVISA, ${ }^{42}$ recommends a correlation coefficient equal to or greater than 0.99. Therefore, the $r$ value was found around 1, indicating that the method showed a good linear fit and that the measurement results obtained were directly proportional to analyte concentration in the range $5-800 \mu \mathrm{g} \mathrm{mL} \mathrm{m}^{-1}$. The coefficient of determination $\left(\mathrm{r}^{2}\right)$ indicated that the response of the straight line equation for calculating the concentration of the plumieride marker was $99.96 \%$.

Precision is the assessment of the closeness of the results obtained from multiple measurements of a series of homogeneous samples, under the same conditions, and is calculated using the coefficient of variation. ${ }^{41,42}$ Repeatability was determined by analysis of three standard solutions containing plumieride at a concentration of $360 \mu \mathrm{g}$ $\mathrm{mL}^{-1}$. Each analysis was performed five times in the same vial to give a total of 15 injections. The method showed good repeatability, the coefficient of variation did not exceed the value of $0.24 \%$, presenting lower than specified by RE Resolution No. 899 that specifies the current limit of the coefficient of variation of $5.0 \% .^{42}$

The LOD and LOQ found for plumieride was $1 \mu \mathrm{g} \mathrm{mL}^{-1}$ and 2 $\mu \mathrm{g} \mathrm{mL} \mathrm{L}^{-1}$, respectively. Accuracy is the degree of agreement between individual results in a particular test and a reference value accepted as true value..$^{37,41}$ The accuracy, in terms of recovery, was performed by spiking a known extraction solution with standard at specific concentration and then determined by HPLC method. The mean recovery and the $\%$ RSD for the plumieride were calculated. A mean recovery of $98.5 \%$ with RSD of $3.3 \%$ was obtained. These results are within the acceptable variation range $(70-120 \%)$ for recovery experiments according to literature. ${ }^{38}$ The coefficients of variation values were relatively low, around $3.3 \%$. These values are in accordance with the acceptance criteria for validation of an analytical 
method described in literature, making the methodology validated for the quantification of the marker in the extraction and fractions of flowers of $A$. cathartica. ${ }^{38,39}$ The specificity is the ability of a method to differentiate a compound in the presence of other components in the sample..$^{42}$ The specificity was found $97.32 \%$. The linearity values, precision and accuracy results indicated that the established method can be well used in the quality control to analyze plumieride in extracts obtained from this plant drug. Plumieride was selected as chemical marker for analytical method validation due to its high yields and pharmacological activities. Chemical markers are used for identification and quality control of herbal medicines. They also can be applied for pharmaceutical and cosmetic products containing the same herbal drug. ${ }^{43}$

\section{Extraction process}

HPLC quantitation of plumieride in A. cathartica flowers extracts obtained by MAE and CSE with ethanol and ethyl acetate was based on the validated method established in this study. The results of mean concentration, standard deviation and relative standard deviation of plumieride are shown in Tables 1, 2 and 3.

The recoveries of plumieride obtained with ethyl acetate are higher than those obtained with ethanol for both extraction methods. Also, less interfering substances were detectable by HPLC using ethyl acetate as solvent, this suggest that ethyl acetate can extract plumieride more selectively than ethanol. However, ethanol extract bigger amounts of extract mass, leading to a final content of plumieride greater than ethyl acetate, as can be seen by the results of plumieride per gram of dried flowers.

In order to obtain an efficient extraction method, MAE parameters that potencially influences the yields of plumieride were evaluated and optimized (Table 1). The standardized Pareto chart was employed to determine the influence of the parameters on the yield of plumieride (Figure 2). A standardized Pareto chart consists of bars with a length proportional to the absolute value of the estimated effects and are displayed in order of the size of the effects, with the largest effects on top. The vertical line in the chart indicates the minimum statistically significant effect magnitude for $95 \%$ confidence level. Effects with bars smaller than the critical t-value are considered as no significant and not affecting the response variables. From the data obtained, it is found that time and power does not influence the content of plumieride with ethanol (Figure 2A). However, using ethyl acetate a significant increase in plumieride yields can be notice with the increase of ET, indicating that time directly influences the plumieride extraction, as can be seen in Figure 2B.

To investigate the interactive effects of the independent variables and their mutual interaction on the yield of plumieride a two factorsthree level Box-Behnken response surface analysis was employed. The three-dimensional surface plot is drawn in Figure 3 and shown the interaction between the MP and ET on the yield of plumieride per gram of dry flowers. Statistical analyses with different model equations (first-order, second order quadratic) revealed a poor fit between RSM model-predicted and observed values of target response. From the surface response plot (Figure 3A) obtained with ethanol ANOVA data applied to ET and MP it was observed that the time $(p=0.524504)$ and power $(p=0.200182)$ had no significant influence on the yields of plumieride per gram of dry flowers. So, the optimal microwave condition for ethanol as extraction solvent at $50{ }^{\circ} \mathrm{C}$ was MP of $200 \mathrm{~W}$ and ET of $5 \mathrm{~min}$.

On the other hand, a second-order model was fitted to the results obtained from the ethyl acetate extracts and model coefficients were evaluated to ascertain significance. $\mathrm{R}^{2}$ of the model was 0.9207 ,

Table 1. Experimental design of plumieride yields obtained by MAE processes varying time and power at $50{ }^{\circ} \mathrm{C}$

\begin{tabular}{|c|c|c|c|c|c|}
\hline Nos. & Extraction time (min) & Microwave Power (W) & $\begin{array}{c}\text { Plumieride } \mathrm{mg} / \mathrm{g} \\
\text { extract } \pm \mathrm{s}(\mathrm{RSD} \%)\end{array}$ & $\begin{array}{c}\text { Extraction yield of } \\
\text { plumieride }(\%)\end{array}$ & $\begin{array}{c}\text { Plumieride } \mathrm{mg} / \mathrm{g} \\
\text { dry flowers }\end{array}$ \\
\hline \multicolumn{6}{|c|}{ Ethanol } \\
\hline E1 & 5 & 100 & $162,17 \pm 0,83(0,51)^{\mathrm{a}, \mathrm{b}}$ & 16,22 & $35,63^{a, b}$ \\
\hline $\mathrm{E} 2$ & 5 & 200 & $189,25 \pm 11,05(5,84)^{\mathrm{a}}$ & 18,93 & $42,84^{\mathrm{a}, \mathrm{b}}$ \\
\hline E3 & 5 & 300 & $151,60 \pm 6,9(4,55)^{\mathrm{b}, \mathrm{c}, \mathrm{e}, \mathrm{g}}$ & 15,16 & $36,21^{\mathrm{a}, \mathrm{b}}$ \\
\hline E4 & 10 & 100 & $178,60 \pm 12,34(6,91)^{\mathrm{a}, \mathrm{e}, \mathrm{f}}$ & 17,86 & $45,20^{\mathrm{a}}$ \\
\hline E5 & 10 & 200 & $159,50 \pm 4,77(2,99)^{\mathrm{b}, \mathrm{c}, \mathrm{f}}$ & 15,61 & $41,36^{\mathrm{a}, \mathrm{b}}$ \\
\hline E6 & 10 & 300 & $131,27 \pm 6,93(5,28)^{\mathrm{g}}$ & 13,13 & $34,25^{\mathrm{b}}$ \\
\hline E7 & 20 & 100 & $143,68 \pm 0,81(0,57)^{\mathrm{b}, \mathrm{g}}$ & 14,37 & $39,33^{\mathrm{a}, \mathrm{b}}$ \\
\hline E8 & 20 & 200 & $153,99 \pm 2,22(1,44)^{\mathrm{b}, \mathrm{e}, \mathrm{g}}$ & 15,40 & $40,03^{\mathrm{a}, \mathrm{b}}$ \\
\hline E9 & 20 & 300 & $141,42 \pm 6,45(4,56)^{\mathrm{b}, \mathrm{g}}$ & 14,14 & $41,88^{\mathrm{a}, \mathrm{b}}$ \\
\hline \multicolumn{6}{|c|}{ Ethyl acetate } \\
\hline A1 & 5 & 100 & $247,08 \pm 8,28(3,35)^{1}$ & 24,71 & $12,27^{1}$ \\
\hline A 2 & 5 & 200 & $256,15 \pm 23,75(9,27)^{1}$ & 25,62 & $13,34^{1}$ \\
\hline A3 & 5 & 300 & $239,67 \pm 2,60(1,09)^{1}$ & 23,97 & $13,20^{1}$ \\
\hline A4 & 10 & 100 & $277,54 \pm 0,73(0,26)^{1}$ & 27,75 & $15,35^{1}$ \\
\hline A5 & 10 & 200 & $328,98 \pm 14,70(4,47)^{2}$ & 32,90 & $19,21^{2}$ \\
\hline A6 & 10 & 300 & $365,36 \pm 0,88(0,24)^{2,3}$ & 36,54 & $21,59^{2,3}$ \\
\hline A7 & 20 & 100 & $384,81 \pm 5,97(1,55)^{3,4}$ & 38,48 & $24,52^{3}$ \\
\hline A 8 & 20 & 200 & $365,45 \pm 17,89(4,89)^{3,4}$ & 36,55 & $24,80^{3}$ \\
\hline A9 & 20 & 300 & $362,21 \pm 4,31(1,19)^{3,4}$ & 36,22 & $23,61^{3}$ \\
\hline
\end{tabular}

Results are expressed as mean value \pm standard deviation. Same letters and numbers refer to means not statistically different ( $>0.05$ ). 

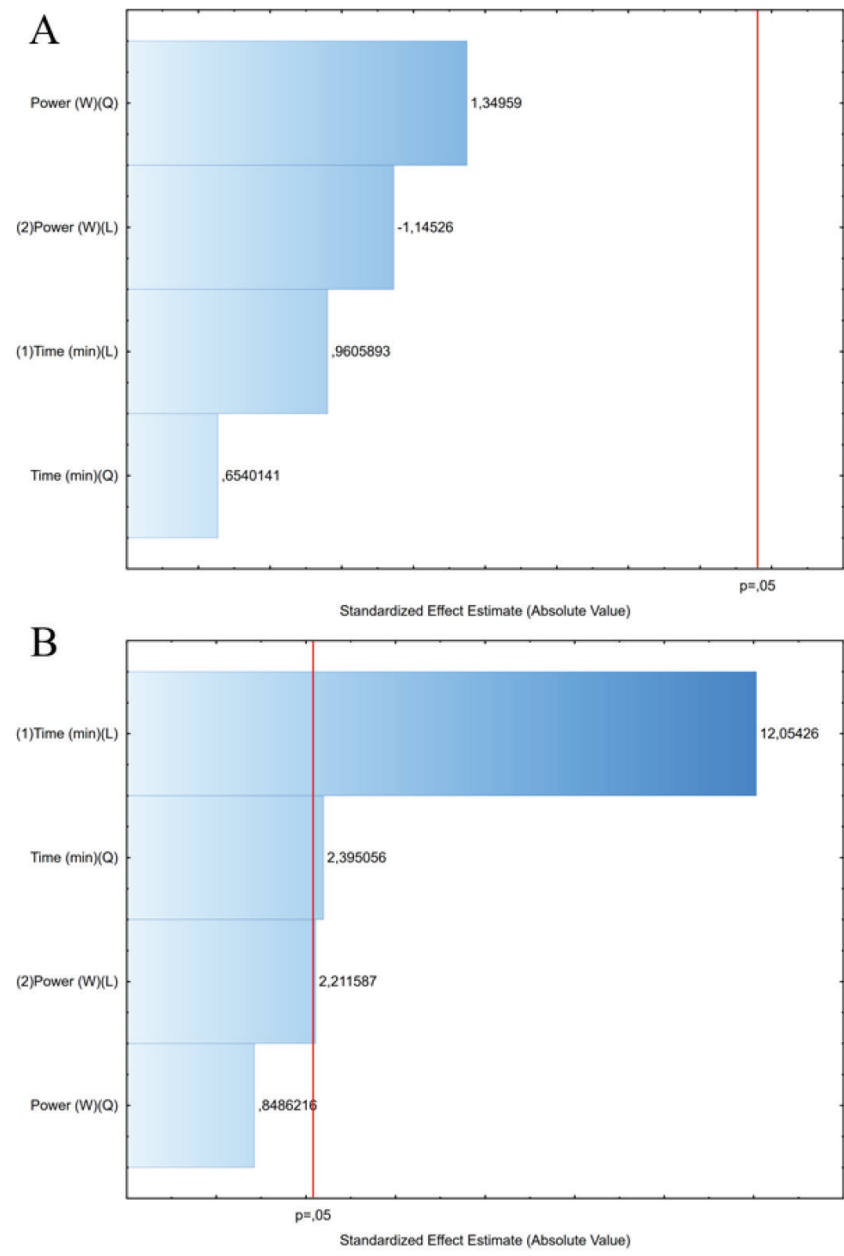

Figure 2. Pareto chart of standardized effects on the plumieride yields in extracts obtained from A. cathartica flowers by MAE with: (A) ethanol and (B) ethyl acetate

which implied that $92.07 \%$ of the total variation could be explain by the model, and it was reasonable to use the regression model to analyze the trend in the response. The predictive model equation for plumieride concentration response, formulated using linear and quadratic coefficients, is as follows:

$Y=19.28778+5.68960 X_{1}+1.04387 X_{2}+0.99698 X_{1}^{2}$

where $Y$ is the yield of plumieride in $\mathrm{mg} \mathrm{g}^{-1}$ dry flower, $X_{1}$ and $X_{2}$ are ET and MP, respectively.

From the observation of the extractions obtained with ethyl acetate (Figure 3B), it can be seen that the extraction yields of plumieride increased with the increase of the ET $(\mathrm{p}=0.000000)$, with less significant influence of MP ( $p=0.045518)$. The model reveals that ET had a linear effect to increase the yield of plumieride. According to equation (1), it was predicted that a maximum yield of plumieride of $25.1 \mathrm{mg} \mathrm{g}^{-1}$ dry flower was appeared under the following extraction conditions: MP of $300 \mathrm{~W}$ and ET of $20 \mathrm{~min}$. From the extractions obtained with ethyl acetate, can be observed that the yield of plumieride obtained with $10 \mathrm{~min}$ and MP of $300 \mathrm{~W}$ $\left(21.59 \mathrm{mg} \mathrm{g}^{-1}\right)$ had no significant difference $(\mathrm{p}>0.05)$ compared with those obtained with twice the ET (23.61 $\left.\mathrm{mg} \mathrm{g}^{-1}\right)$, which suggested that this point was near the optimal point. Therefore, the best microwave condition for ethyl acetate was MP of $300 \mathrm{~W}$ and ET of $10 \mathrm{~min}$. The corresponding predicted value was $24.7 \mathrm{mg} \mathrm{g}^{-1}$, which was in close agreement with the experimental yield.
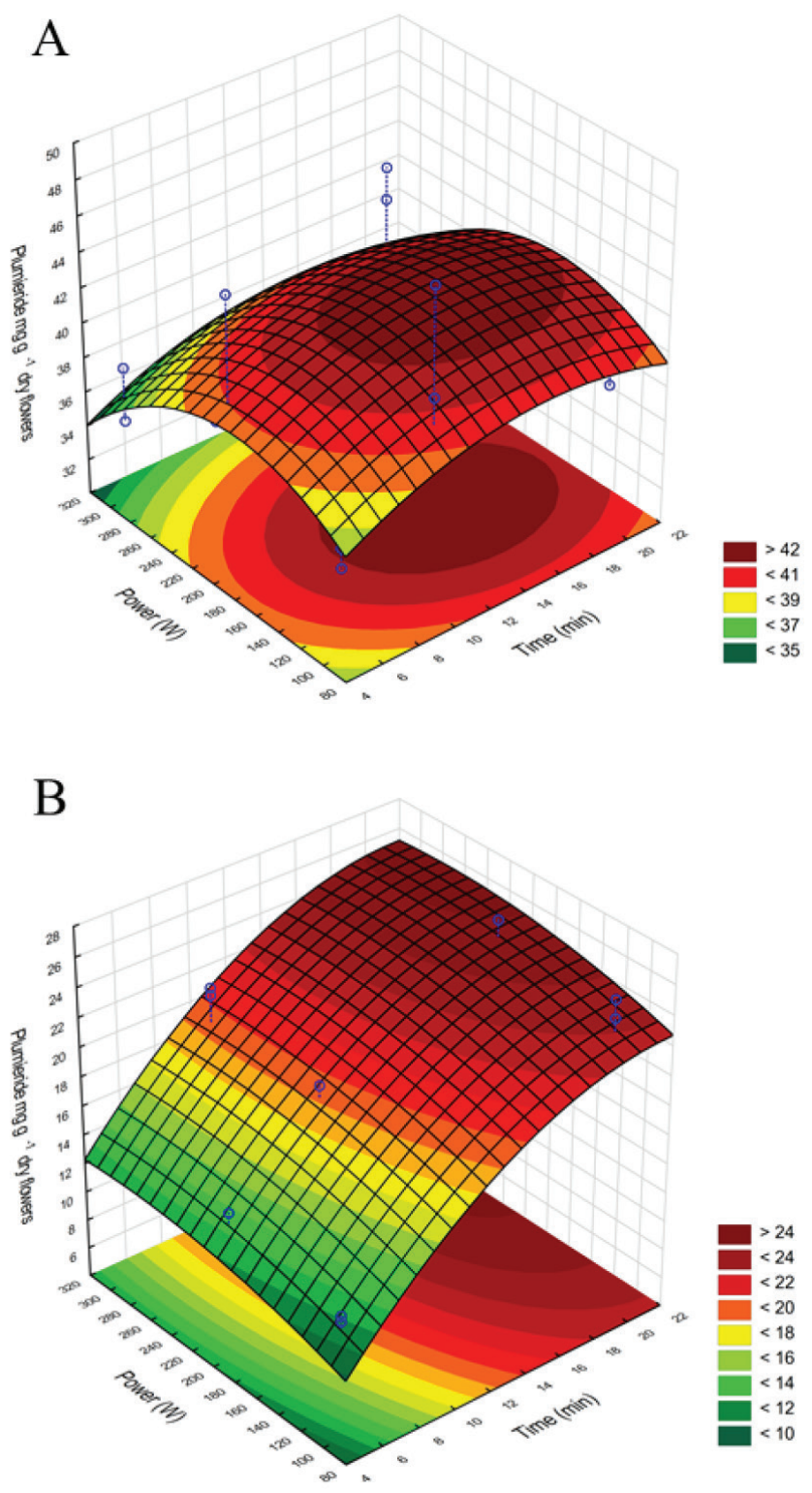

Figure 3. Surface response plot for plumieride yield obtained with ethanol (A) and ethyl acetate (B) by MAE at $50^{\circ} \mathrm{C}$

\section{Influence of temperature extraction on the yield of plumieride}

In order to optimize and investigate the influence of temperature in the extraction condition, it was performed three additional analysis for each solvent, with three different ET (5, 10 and $20 \mathrm{~min}$ ), at temperature $76{ }^{\circ} \mathrm{C}$, with fixed MP of $200 \mathrm{~W}$. The results are shown in Table 2.

Comparing the results of the extractions obtained with ethanol at $50^{\circ} \mathrm{C}$ and $76^{\circ} \mathrm{C}$, it can be seen that temperature significantly influence $(p=0.000035)$ the yield of plumieride per gram of dry flowers. Meanwhile, ET not significantly $(\mathrm{p}>0.05)$ influence the amount of plumieride. This can be confimerd by the Pareto chart of standardized effect (Figure 4). Temperature also increase the mass yield extract in 61,52 and $47 \%$, respectevely for 5, 10 and $20 \mathrm{~min}$, compared with those in the same conditions at $50^{\circ} \mathrm{C}$. Higher extraction temperature possibly enhances the spread ability and solubility, which is beneficial to extract sugars and others compounds such as flavonoids, thus contributing to the increase of the extract weight. Therefore, for the extraction with ethanol the best condition was 5 minute of ET, MP of $200 \mathrm{~W}$ and at temperature of $76^{\circ} \mathrm{C}$. 
Table 2. Single factor conditions with plumieride yields obtained by MAE processes varying time and solvent at $76^{\circ} \mathrm{C}$, with fixed microwave power of $200 \mathrm{~W}$

\begin{tabular}{|c|c|c|c|c|}
\hline Nos. & Extraction time (min) & $\begin{array}{c}\text { Plumieride mg/g } \\
\text { extract } \pm \mathrm{s}(\mathrm{RSD} \%)\end{array}$ & $\begin{array}{c}\text { Extraction yield of } \\
\text { plumieride }(\%)\end{array}$ & $\begin{array}{c}\text { Plumieride } \mathrm{mg} / \mathrm{g} \\
\text { dried flowers }\end{array}$ \\
\hline \multicolumn{5}{|c|}{ Ethanol } \\
\hline EO1 & 5 & $143,15 \pm 0,15(0,10)^{\mathrm{a}, \mathrm{b}}$ & 14,32 & $52,30^{\mathrm{c}}$ \\
\hline $\mathrm{EO} 2$ & 10 & $126,17 \pm 0,15(0,12)^{\mathrm{b}}$ & 12,62 & $49,72^{\mathrm{c}}$ \\
\hline $\mathrm{EO} 3$ & 20 & $147,81 \pm 0,21(0,14)^{\mathrm{a}}$ & 14,78 & $56,60^{\mathrm{c}}$ \\
\hline \multicolumn{5}{|c|}{ Ethyl acetate } \\
\hline $\mathrm{AO} 1$ & 5 & $417,86 \pm 0,26(0,06)$ & 41,79 & 31,95 \\
\hline $\mathrm{AO} 2$ & 10 & $438,60 \pm 0,36(0,08)^{\mathrm{d}}$ & 43,86 & 36,28 \\
\hline $\mathrm{AO} 3$ & 20 & $465,20 \pm 0,75(0,16)^{\mathrm{d}}$ & 46,52 & 42,18 \\
\hline
\end{tabular}

Results are expressed as mean value \pm standard deviation. Same letters refer to means not statistically different $(\mathrm{p}>0.05)$

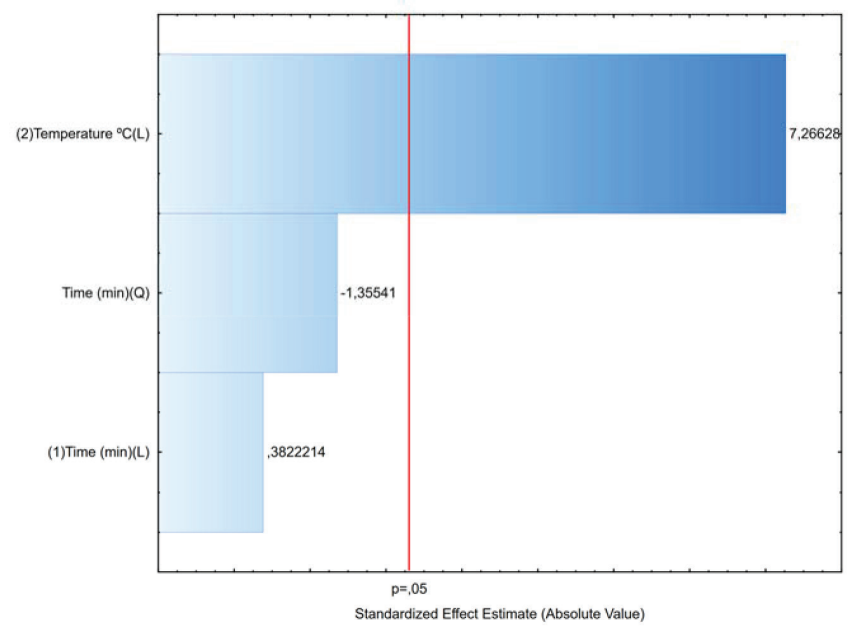

Figure 4. Pareto chart of standardized effects on plumieride yields in extracts obtained from A. cathartica flowers by MAE with ethanol at 50 and $76^{\circ} \mathrm{C}$

From the results obtained with ethyl acetate, it was found that time and temperature significantly $(\mathrm{p}<0.05)$ increase the amount of extract mass in 47, 42 and 34\%, respectively for 5, 10 and $20 \mathrm{~min}$, compared with those in the same conditions at $50^{\circ} \mathrm{C}$. It can be found that the yield of plumieride significantly increased with the increase of ET and temperature. This fact could be confirmed statistically by the p-values obtained from ANOVA calculations (time: 0.000008 and temperature: 0.000000$)$. All the means were different $(\mathrm{p}<$ 0.05 ) and the highest amount of plumieride obtained with ethyl acetate was $42 \mathrm{mg} \mathrm{g}^{-1}$ of dry flowers. It can be concluded that for the extraction with ethyl acetate the optimun extraction conditions were ET of 20 minutes with MP of $200 \mathrm{~W}$ and temperature of 76 ${ }^{\circ} \mathrm{C}$. In this conditions the yield of plumieride in the extract was $46 \%$. This increase in extraction yield of plumieride maybe due to the high temperature in MAE that increased the desorption of analytes from active site in the matrix, and also cause a decrease on the surface tension and viscosity of the solvent, which improved the capacity to solubilize analytes and improves the efficiency of extraction. ${ }^{44}$
In general studies published with $A$. cathartica works with aerial parts using conventional solvent extraction. Due this lack of information it became difficult to made a proper comparison. In this study, it was possible to isolate plumieride with $9 \%$ of yield with respect to the mass of dried flowers. In the literature, it can be found yields ranging from 0,13 to $1,6 \% .^{20,35}$

\section{Comparison of MAE with CSE}

The yields of plumieride in the extracts from A. cathartica flowers using MAE and CSE methods is presented in Table 1, 2 and 3. The results indicated that MAE showed a greater extraction capacity of plumieride in both solvents compared to CSE. After optimization in MAE parameters, plumieride yields was significantly $(\mathrm{p}<0.05)$ higher than that obtainde with CSE.

The higher extraction yield of plumieride with MAE could be due the unique mechanism of extraction that uses microwave energy to heat rapidly and efficiently the solvents and the vegetable matrix that contains amount of water that strongly absorbs microwave energy, leading to cell disruption which increases the penetration of the solvent inside the matrix accelerating the dissolution of intracellular effective components and increasing the yield of the extraction..$^{29,30}$ The main advantages of MAE over conventional extraction techniques are reduced solvent consumption and ET, moderately high recoveries, good reproducibility and minimal sample manipulation in the extraction process. ${ }^{45}$ In conclusion, compared with other extraction methods, MAE had the highest extraction yield of plumieride from the A. cathartica flowers with shortest extracting time.

\section{CONCLUSION}

The present work established an improved and optimized MAE method for extracting plumieride from A. cathartica flowers. Also, proved to be fast and efficient compared with CSE. The extraction yield of plumieride was improved greatly using a RSM with two factors at three levels. ANOVA was used to examine the RSM experimental data. Under optimal MAE conditions this approach could provide higher contents of plumieride, i.e. ethyl acetate as extraction solvent, MP $200 \mathrm{~W}$, ET $20 \mathrm{~min}$ and $76^{\circ} \mathrm{C}$, plumieride yield

Table 3. Plumieride yields obtained by conventional extraction process with ethanol and ethyl acetate for seven days

\begin{tabular}{lccc}
\hline Extract & Plumieride $\mathrm{mg} / \mathrm{g}$ extract $\pm \mathrm{s}(\mathrm{RSD} \%)$ & Extraction yield of plumieride (\%) & Plumieride mg/g dried flowers \\
\hline Ethyl acetate & $216,8 \pm 1,82(0,84)^{\mathrm{a}}$ & 21,68 & $18,52^{\mathrm{a}}$ \\
Ethanol & $116,9 \pm 0,19(0,16)^{\mathrm{b}}$ & 11,69 & $44,89^{\mathrm{b}}$ \\
\hline
\end{tabular}

Results are expressed as mean value \pm standard deviation. Same letters and numbers refer to means not statistically different ( $\mathrm{p}>0.05$ ). 
was $42 \mathrm{mg} \mathrm{g}^{-1}$ of dry flowers, and with ethanol as extraction solvent this yield reached $56 \mathrm{mg} \mathrm{g}^{-1}$ of dry flowers. Microwave irradiation improved the cell rupture of the plant materials and enhanced the efficiency of the solvent on the extraction of the analyte from the plant matrix. Together with MAE extraction, a simple, fast, selective, precise and accurate HPLC-PAD method has been developed for analysis and quantification of plumieride in extracts of $A$. cathartica flower. This method can be useful to the pharmaceutical analysis of iridoids in extracts of plants due to pharmacologically effect important of this class of compounds. Our results also contribute to future experiments with MAE system as a plant extraction technique.

\section{ACKNOWLEDGMENTS}

This study was supported by government grants from Conselho Nacional de Desenvolvimento Científico e Tecnológico (CNPq) and Fundação de Amparo à Pesquisa e Inovação do Estado de Santa Catarina (FAPESC). Universidade do Vale de Itajaí (UNIVALI) also provided financial support (fellowship).

\section{REFERENCES}

1. Cragg, G. M.; Grothaus, P. G.; Newman, D. J.; J. Nat. Prod. 2014, 77, 703.

2. Tiwari, S.; J. Nat. Prod. 2008, 1, 27.

3. Elfahmi; Woerdenbag, H. J.; Kayser, O.; J. Herb. Med. 2014, 4, 51.

4. Moloney, M. G.; Trends Pharmacol. Sci. 2016, 37, 689.

5. Calixto, J. B.; Braz. J. Med. Biol. Res. 2005, 33, 179.

6. WHO; World Health Organization - Traditional Medicine, WHO Media Centre, 2008.

7. Prabhadevi, V.; Sathish, S. S.; Johnson, M.; Venkatramani, B.; Janakiraman, N.; Asian Pac. J. Trop. Biomed. 2012, 1, S550.

8. Newman, D. J.; Cragg, G. M.; J. Nat. Prod. 2012, 75, 311.

9. Endress, M. E.; Bruyns, P. V.; Bot. Rev. 2000, 66, 1.

10. Gonçalves, E. G.; Lorenzi, H.; Morfologia vegetal: organografia e dicionário ilustrado de morfologia das plantas vasculares, Instituto Plantarum de Estudos da Flora: Nova Odessa, 2007.

11. Anderson, J. E.; Chang, C. J.; McLaughlin, J. L.; J. Nat. Prod. 1988, 51, 307.

12. Ganapaty, S.; Rao, D. V.; Venkata, R. D.; Indian J. Pharm. Sci. 1988, 50, 134.

13. Schmidt, D. F. N.; Yunes, R. A.; Schaab, E. J.; Malheiros, A.; CechinelFilho, V.; Franchi Jr, G. C.; Nowill, A. E.; Cardoso, A. A.; Yunes, J. A.; J. Pharm. Pharm. Sci. 2006, 9, 200.

14. Ghisalberti, E. L.; Phytomedicine 1998, 5, 147.

15. Dixit, S. N.; Tripathi, S. C.; Ojaha, T. N.; J. Antibac. Antifungal Agents. 1982, 10, 197

16. Dinda, B.; Debnath, S.; Harigaya, Y.; Chem. Pharm. Bull. 2007, 55, 159.

17. Kuigoua, G. M.; Kouam, S. F.; Ngadjui, B. T.; Schulz, B.; Green, I. R.; Choudhary, M. I.; Krohn, K.; Planta Med. 2010, 76, 620.

18. Pandeti, S.; Sharma, K.; Bathula, S. R.; Tadigoppula, N.; Phytomedicine 2014, 21, 333 .

19. Dobhal, M. P.; Li, G.; Gryshuk, A.; Granham, A.; Bhatanager, A. T.;
Khaja, S. D.; Joshi, Y. C.; Sharma, M. C.; Oseroff, A.; Pandey, R. K.; J. Org. Chem. 2004, 69, 6165.

20. Tiwari, T. N.; Pandey, V. B.; Dubey, N. K.; Phytother. Res. 2002, 16 , 393.

21. Nascimento, F. G.; Faqueti, A.; Wilhelm, J. F.; Wittkowski, C.; Tomczak, F. D.; Borges, S. L.; Yunes, R. A.; Franchi Jr, G. C.; Nowill, A. E.; Cechinel-Filho, V.; Machado, M. S.; Freitas, R. A.; Malheiros, A.; Rev. Bras. Farmacogn. 2014, 24, 545 .

22. Rebouças, S. O.; Silva, J.; Bertoni, R. S.; Decker, N.; Santos, M. S.; Rossatto, R. R.; Corrêa, D. S.; Ferraz, A. B. F.; J. Ethnopharmacol. 2013, 147, 474 .

23. Pankoke, H.; Buschmann, T.; Müller C.; Phytochemistry 2013, 94, 99.

24. Gupta, R. S.; Bhatnager, A. K.; Joshi, Y. C.; Sharma, R.; Sharma, A.; Phytomedicine 2004, 11, 169.

25. Afifi, M. S.; Salama, O. M.; Gohar, A. A.; Marzouk, A. M.; Bull. Pharm. Sci. 2006, 29, 215.

26. Adam, G.; Khor, N. H.; Bergner, C.; Lien, N. T.; Phytochemitry 1979, $18,1399$.

27. Sticher, O.; Nat. Prod. Rep. 2008, 25, 517.

28. Ong, E. S.; Apandi, S. N. B.; Electrophoresis 2001, 22, 2723.

29. Spigno, G.; De Faveri, D. M.; J. Food Eng. 2009, 93, 210.

30. Wang, L.; Weller, C. L.; Trends Food Sci. Technol. 2006, 17, 300.

31. Camel, V.; Analyst 2001, 126, 1182.

32. Dahmoune, F.; Nayak, B.; Moussi, K.; Remini, H.; Madani, K.; Food Chem. 2015, 166, 585.

33. Thirugnanasambandham, K.; Sivakumar, V.; Prakash Maran, J.; Int. J. Biol. Macromol. 2015, 72, 1.

34. Zhang, Y.; Li, H.; Ma, Y.; Jin, Y.; Kong, G.; Lin, J.; Talanta 2014, 129, 404.

35. Malheiros, A.; Schuquel, I. T. A.; Vidotti, G. J.; Quim. Nova 1997, 20, 457.

36. Silverstein, R. M.; Bassler, G. C.; Morrill, T. C.; Identificação espectrométrica de compostos orgânicos, $5^{\text {th }}$ ed., Guanabara Koogan: Rio de Janeiro, 1994.

37. Rijke, E.; Out, P.; Niessen, W. M. A; Ariese, F.; Gooijer, C.; Brinkman, U. A. T.; J. Chromatogr. A. 2006, 1112, 31.

38. Ribani, M.; Bottoli, C. B. G.; Collins, C. H.; Jardim, I. C. S. F.; Melo, L. F. C.; Quim. Nova 2004, 27, 771.

39. Chandran, S.; Singh, R. S.; Pharmazie 2007, 62, 4.

40. Bai, X. L.; Yue, T. L.; Yuan, Y. H.; Zhang, H. W.; J. Sep. Sci. 2010, 33, 3751.

41. Rozet, E.; Ceccato, A.; Hubert, C.; Ziemons, E.; Oprean, R.; Rudaz, S.; Boulanger, B.; Hubert, P.; J. Chromatogr. A. 2007, 1158, 111.

42. ANVISA; Agência Nacional de Vigilância Sanitária, Resolução (RE) $n^{\circ} 899$, de 29 de maio de 2003. Determina a publicação do "Guia para validação de métodos analíticos e bioanalíticos". Diário Oficial da República Federativa do Brasil. Brasília, DF, 2003.

43. Funasaki, M.; Barroso, H. S.; Fernandes, V. L. A.; Menezes, I. S.; Quim. Nova 2016, 39, 194.

44. Xiao, X.; Wang, J.; Wang, G.; Wang, J.; Li, G.; J. Chromatogr. A. 2009, 1216,8867

45. Armenta, S.; Garrigues, S.; de la Guardia, M.; Trends Anal. Chem. 2008 , $27,497$. 